\title{
Coding and encoding rights in internet infrastructure
}

\author{
Stefania Milan \\ University of Amsterdam, Netherlands
}

\author{
Niels ten Oever \\ Article 19 \& University of Amsterdam, Netherlands \\ Published on 17 Jan 2017 | DOI: 10.14763/2017.1.442
}

\begin{abstract}
This article explores bottom-up grassroots ordering in internet governance, investigating the efforts by a group of civil society actors to inscribe human rights in internet infrastructure, lobbying the Internet Corporation for Assigned Names and Numbers. Adopting a Science and Technology Studies (STS) perspective, we approach this struggle as a site of contestation, and expose the sociotechnical imaginaries animating policy advocacy. Combining quantitative mailing-list analysis, participant observation and qualitative discourse analysis, the article observes civil society in action as it contributes to shape policy in the realm of institutional and infrastructure design.
\end{abstract}

Keywords: Internet Corporation for Assigned Names and Numbers (ICANN), Civil society, Human rights, Sociotechnical imaginaries, Bottom-up design

\section{Article information}

Received: 28 May 2016 Reviewed: 15 Sep 2016 Published: 17 Jan 2017

Licence: Creative Commons Attribution 3.0 Germany

Funding: This project has received funding from the European Research Council (ERC) under the European Union's Horizon 2020 research and innovation programme (grant agreement No 639379) Competing interests: The author has declared that no competing interests exist that have influenced the text.

URL: http://policyreview.info/articles/analysis/coding-and-encoding-rights-internet-infrastructure

\section{ACKNOWLEDGMENTS:}

The authors would like to wholeheartedly thank Frédéric Dubois, Mikkel Flyverbom, Seda Gürses, and Joris van Hoboken for the precious comments at the review stage, as well as Francesca Musiani, Dmitry Epstein and Christian Katzenbach for the inspiration. They would also like to acknowledge the support of the Digital Methods Initiative at the University of Amsterdam. $\square$ 
'Does ICANN violate human rights?', asked a 2014 report by the Council of Europe (CoE), questioning whether the policies and operations of the Internet Corporation for Assigned Names and Numbers (ICANN) unintentionally infringe users' right to privacy, freedom of association, and freedom of expression. ICANN is a nonprofit corporation in charge of the coordination of a public resource, the internet's underlying address book or Domain Name System (DNS). The CoE report was the first exogenous attempt to gauge ICANN's policymaking in light of human rights, fundamental freedoms and democratic standards (Zalnieriute \& Schneider, 2014). Two years down the road, human rights are not only being encoded in the organisational structure by means of inclusion in the bylaws (Appelman, 2016); they also permeate much of the policy development within ICANN. This ongoing multistakeholder process has been driven, among others, by a small group of civil society actors, who set up to inscribe human rights into names and numbers, protocols and standards, both within ICANN and the Internet Engineering Task Force (Cath, 2015).

Internet governance embraces the global coordination of the DNS and internet addresses, but also various other 'environments with low formalization, heterogeneous organizational forms, large numbers of actors and massively distributed authority and decision-making power' (Van Eeten \& Mueller, 2013, p. 730). Here, we approach it as a 'politically contested process of meaning making in which past and future technological projects are framed in a particular light' (McCharty, 2011, p. 90). This article explores the meaning-making and discursive role of the organised civil society in institutional and infrastructure design, focusing on the management within ICANN of the DNS, an inherent part of internet infrastructure, and its relation to human rights values. We investigate civil society engagement with the organisation, in particular following the transition of the stewardship over ICANN from the US Congress to the global multistakeholder community announced in early 2014, and map the distinct articulations of the human rights discourse that emerged in relation to internet infrastructure and the organisation itself. In doing so, we adopt the disciplinary lenses of Science and Technology Studies, for STS allows us to address technology as a site of contestation, focusing on its unremitting interplay with the social and on the controversies that might emerge. STS allows us to understand internet governance 'as a normative "system of systems"', unpacking 'the micro practices of governance as mechanisms of distributed, semi-formal or reflexive coordination, private ordering, and use of internet resources' (Epstein, Katzenbach, \& Musiani, 2016). It empowers us to move away from a 'focus on institutions as agents' towards investigating 'the agency of technology designers, policy-makers, and users as those interact in a distributed fashion, with technologies, rules, and regulations, leading to unintended consequences with systemic effects' (Ibid.; see also Musiani, 2015).1

We see this civil society-led struggle to inscribe human rights in internet infrastructure as an instance of bottom-up design, defined as the process of enshrining 'radical' (Milan, 2014b) or unconventional policy preferences - which sprung out of technological practice and cultures such as the hacker subculture 2 - into governance fora and institutions. 3 Our definition owes to the STS notions of social shaping of technology (e.g., MacKenzie \& Wajcman, 1999) and coproduction (e.g., Jasanoff, 2004), which stress the role of users in technology innovation and in the diffusion of new ideas. It is also inspired by the disciplines of critical design (e.g., Dunne \& Raby, 2001) and critical technology practice, especially where these focus on culturally embedded discursive practices (e.g., Agre, 1997; Dourish, 2001).

Bottom-up design seeks to intervene in the organisational process that some STS scholars have termed 'ordering', which entails the negotiation of plurality and alternatives within a given context (Mol, 2001).4 Organisations like ICANN can thus be seen as materially heterogeneous 
institutions in charge of ordering and arranging difference (Law, 1994b; Woolgar \& Neyland, 2013). Following Jasanoff, regulations like ICANN bylaws are to be understood as 'devices that order and reorder society' (2004, p. 14). Looking at these ordering practices allows us to capture 'the normative effect of mundane practices and daily routines' that characterise internet governance as a series of 'hybrid configurations constantly reshaping their purposes and procedures in order to connect and mobilise objects, subjects and other elements, constituted and positioned relationally, around particular issues' (Epstein et al., 2016). Thus, bottom-up design can be seen as a way of 'making institutions' while/by 'making discourses', that is to say 'producing new languages or modifying old ones so as to find words for novel phenomena' (Jasanoff, 2004, pp. 39-41). In the context of this article, objects of ordering are internet infrastructure and the associated values as they bear on decision-making and infrastructure/organisation design.

Practitioners of bottom-up design typically operate as critical communities who 'seek acceptance of a new conceptualization of a problem', and try to shape the way people think about it (Rochon, 1998, p. 22). An important source of legitimacy for such critical communities is expertise, including technical practice (Ibid.). At the core of bottom-up design is a (variably explicit) connection with technology-oriented movements like the open-source software community (Hess, 2005), and with critical tech communities engaging with alternative technologies and technical practices (Hintz \& Milan, 2009; Tréguer, Panayotis, \& Söderberg, 2016). These take autonomous technologies as alternative institutions: not just as 'objects of governance, but also as a set of tools for governance' (Musiani, 2016, p. 85 original italics). As such, they represent the source of the cultural and ideological references of an important portion of civil society advocates within ICANN.

Following the STS tradition, we approach the struggle for coding and encoding rights within ICANN as an instance of 'solving a problem of disorder within established cultures' (Jasanoff, 2004, p. 6), where the disorder is a mismatch between a time-honored organisational culture, ICANN's, and the values of part of its community. We take ICANN, and the human rights debate within it, as a site of multi-level contestation (McCharty, 2011) characterised by 'disagreement, negotiation, and the potential for breakdown' (Akrich, 1992, p. 207), and seek to capture the visions and internal diversity of the civil society contingent. We engage in a partial 'sociography' of this process, describing the relationships behind it (Ibid.) and the related 'ordering narratives' (Doolin, 2003), constantly moving between the 'technical' (of both technical infrastructure and organisational mechanisms) and the 'social' (of civil society mobilising) (cf. Bijker \& Law, 1992).

Original data for this article was collected analysing, by means of the Python toolkit BigBang (Benthall, 2015), [NCUC-discuss], the principal mailing list of theNonCommercial Users Constituency (NCUC), the main home for civil society organisations and individuals within ICANN.5 Mailing list analysis was selected for three reasons: first, even though ICANN holds regular face-to-face and teleconference meetings, mailing lists remain a key channel for deliberation and decision-making within the ICANN community; second, participation in the online discussion make differences and conflicts visible; third, language reflects the 'cultural and symbolic understandings surrounding the internet' (McCharty, 2011, p. 90). In addition to the quantitative analysis, we engaged in qualitative discourse analysis of selected e-mails as well as extensive participant observation (2013-present).6

In what follows, we reflect on civil society's engagement in internet governance and introduce the notion of sociotechnical imaginaries, useful to capture the advocates' visions and values. Next, we present ICANN as an organisation in evolution particularly susceptible to 
organisational reform. The third section delves into the empirical analysis, and shows how the progressive inclusion of new civil society advocates in the process caused an expansion of the human rights agenda. We conclude linking these concerted efforts to the recent turn to infrastructure in internet governance (Musiani, Cogburn, DeNardis, \& Levinson, 2016).

\section{CIVIL SOCIETY AND INTERNET GOVERNANCE: EMERGING SOCIO-TECHNICAL IMAGINARIES}

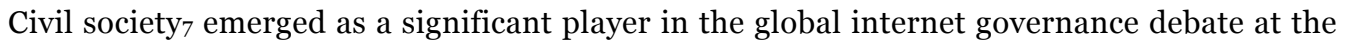
United Nations' World Summit on the Information Society (WSIS, 2003-2005), when it was invited to the negotiation table 'on equal footing' (Hintz, 2009). Ever since, the composite civil society rubric, constituted by individuals and nonprofit organisations, has made its voice heard at the yearlyInternet Governance Forum, a WSIS spin-off for a multistakeholder dialogue on internet-related public policy issues (Mueller, 2010).

Rather than a uniform monolithic entity, civil society is a multifaceted field of action and beliefs where distinct approaches, worldviews and visions of what the internet is and should look like co-exist, not without conflicts. These collective visions or imaginaires link 'intentions and projects as well as utopias and ideologies' (Flichy, 2007, p. 4). They are collective because they tend to be shared by groups and individuals across the world and regardless of national cultures. They can be seen as 'ways of thinking about what infrastructures are, where they are located, who controls them, and what they do' (Parks, 2015, p. 355). These imaginaries, knitting together the 'technological' and the 'social' to say it with STS scholars, emerge from, among other, 'the imaginative faculties, cultural preferences and economic or political resources' of internet users (Jasanoff, 2004, p. 16), and evolve in interaction with the actions and preferences of other actors including governments and industry (see also Bijker, 1997). They originate in users' mundane practices as these shape governance discourses.8 They mirror subtending ideologies, but are also influenced by broader geopolitics such as foreign policy (cf. McCharty, 2011; see also Turner, 2006).

Sociotechnical imaginaries embody a normative, prefigurative dimension. They can be seen as 'a means of relating the local and the present to broader developments and structures of the past or the future' (Hoffmann, Katzenbach, \& Gollatz, 2016). They are at once 'descriptive of attainable futures and prescriptive of the kinds of futures that ought to be attained' (Jasanoff, Kim, \& Sperling, 2007, p. 1). Most importantly, they are instruments of co-production that 'have the power to shape technological design' (Ibid.). As we shall see, ICANN policy-making is shaped in 'bottom-up, consensus-driven, multi-stakeholder' policy development processes where discursive change is functional to issue naming and recognition as well as agenda setting (cf. Stone, 1988; Dery, 2000). Thus, there is a direct line between the visions enshrined in the sociotechnical imaginaries of the various actors, on the one hand, and the concrete outcomes of institutional and infrastructural formation, on the other.

Focusing on sociotechnical imaginaries allows us to observe civil society in action as it contributes to shape policy in infrastructural and institutional design. As the process is ongoing, this article tracks two moments of co-production, namely the emergence of new ideas and the ensuing contestation phase (Jasanoff, 2004). 


\section{ICANN AND THE STRUGGLE FOR HUMAN RIGHTS}

ICANN is a nonprofit organisation incorporated in California whose mission is to 'ensure the stable and secure operation of the internet's unique identifier systems' (ICANN 2016). ICANN is in fact in charge of the management, operation and technical maintenance of a number of databases concerning both 'names' (e.g., root name servers, the DNS) and 'numbers' (e.g., Internet Protocol address spaces such as IPv4/6, the regional registries). Set up in 1998 to manage the Internet Assigned Numbers Authority (IANA) on behalf of the US Department of Commerce (Mueller, 2002), ICANN is at a historical turning point. At its 55thmeeting, in Marrakesh, Morocco (March 2016), the ICANN community voted in support of transitioning the stewardship over the IANA function from the US National Telecommunication and Information Agency (NTIA) to the global multistakeholder community.

ICANN consists of two parts: the corporation that implements policies and procedures to run the infrastructure, and the so-called 'community' that, supported by ICANN staff, develops in a multistakeholder fashion the policies that are implemented by the corporation. Since its inception, ICANN stimulated bottom-up policy development, although the industry still plays a leading role with civil society merely in tow, and the organisation has not been exempt from criticism (Bygrave, 2015; Raymond \& DeNardis, 2015). Civil society involvement dates back to the establishment of the NonCommercial Domain Name Holders Constituency (NCDNHC) in 1999, relabeled NCUC in 2003. NCUC membership, which is free of charge, includes both organisations and individuals, the latter ranging from technical experts and academics to professional advocates and users, with backgrounds as diverse as engineering, law, and development activism. At the time of writing, it counted 118 organisation and 415 individual members from 157 countries.9 NCUC has a policymaking function, and contributes to elect six members in the Council of the Generic Names Supporting Organization, in charge of the policies for Generic Top Level Domains (e.g., .net, .com, .hotel, . ( $\square \square \square \square$.

Notwithstanding the early engagement of civil society in the organisation, human rights remained long at the margins of ICANN, in contrast to governance fora like WSIS and IGF (Jørgensen, 2006). The wind changed direction as a new group of advocates joined ICANN in 2014, following a combination of events such as the leaks by security contractor Edward Snowden of classified documents proving blanket surveillance of internet users by national security agencies (June 2013 onwards); the CoE report on ICANN's responsibility to respect human rights; and most importantly theannouncement, on March 2014, that the United States would release control over the IANA function. Since early 2014, in an unprecedented experiment of 'polycentric governance' (Scholte, 2016), the ICANN community engaged in a major redesign endeavour. It launched, among others, theCross Community Working Group on Enhancing ICANN Accountability (CCWG Accountability), tasked with 'develop[ing] a plan to transition the US government stewardship role with regard to the IANAfunctions and related root zone management'. The IANA transition, and CCWG Accountability in particular, worked as a 'policy window', or an occasion for political participation by civil society advocates (Kingdon, 1995). This policy window represented an opportunity to connect the 'policy niche' of human rights (Milan, 2009), until then largely ignored by the community at large, to a broader process at the core of the organisation's future.

The CoE report was presented at the 50thICANN meeting, in London (June 2014). The ICANN 51 (Los Angeles, October 2014) agenda included a session on human rights co-organised by the $\mathrm{CoE}$ and the ICANNGovernment Advisory Committee (GAC). Two new entities were formed: 
theGAC Working Group on Human Rights and International Law (GAC WG HRIL) and the multistakeholderCrossevoCommunity Working Party on ICANNs Corporate and Social Responsibility to Respect Human Rights (CCWP HR), 10 established as a sub-entity of the NCSG and chaired by the freedom of expression non-governmental organisation Article 19 (recently affiliated to the NCUC). The two operate independently but coordinate their work through joint public meetings. At ICANN 52 in Singapore (February 2015), Article 19 launched the reportICANN's Corporate Responsibility to Respect Human Rights.

At ICANN 53 (Buenos Aires, June 2015) and ICANN 54 (Dublin, October 2015), CCWP HR held both working and outreach sessions with other ICANN constituencies, representing the interests of other communities, e.g. the Intellectual Property (IP) Constituency. Meanwhile, the CCWG Accountability recommended a concrete commitment to human rights in the ICANN posttransition bylaws, but parts of the community pushed back, concerned that a commitment to human rights would broaden ICANN's scope and mission. Eventually, thefinal report by CCWG Accountability, made public on February 2016, recommended that ICANN should commit to respect human rights within its narrow scope and mission; that it should not be forced to actively protect human rights or force external parties to do so; that such commitment is to be included in the ICANN bylaws, but that the specific bylaw would only be enacted pending the development of an adequate framework of interpretation.

The ICANN community vote in support of theIANA stewardship transition proposal, in March 2016, paved the way for the proposed regulations to be reworked into the organisation's bylaws. The bylaws revision concluded phase 1 (or Workstream 1) of the transition. Bylaw (viii), adopted in May 2016 and included in Article 1 Mission, Commitment and Core Values, Section 1.2(b) reads:
(viii) Subject to the limitations set forth in Section 27.2,11 within the scope of its Mission and other Core Values, respecting internationally recognized human rights as required by applicable law. This Core Value does not create, and shall not be interpreted to create, any obligation on ICANN outside its Mission, or beyond obligations found in applicable law. This Core Value does not obligate ICANN to enforce its human rights obligations, or the human rights obligations of other parties, against other parties.

This concluded the contestation phase concerning the inclusion of human rights into the bylaws (Jasanoff, 2004). The NTIA announced in June 2016 its acceptance of the proposal put forward by the global internet multistakeholder community; the actual IANA stewardship transition was completed on 1 October 2016 when the ICANN contract with the US government officially came to an end. As far as human rights are concerned, the ongoing Workstream 2 of the IANA transition requires the development of the framework of interpretation for bylaw (viii), and of a human rights impact assessment instrument for ICANN policies and operations. Figure 1 shows how human rights relate to ICANN's themes and policies/processes. 


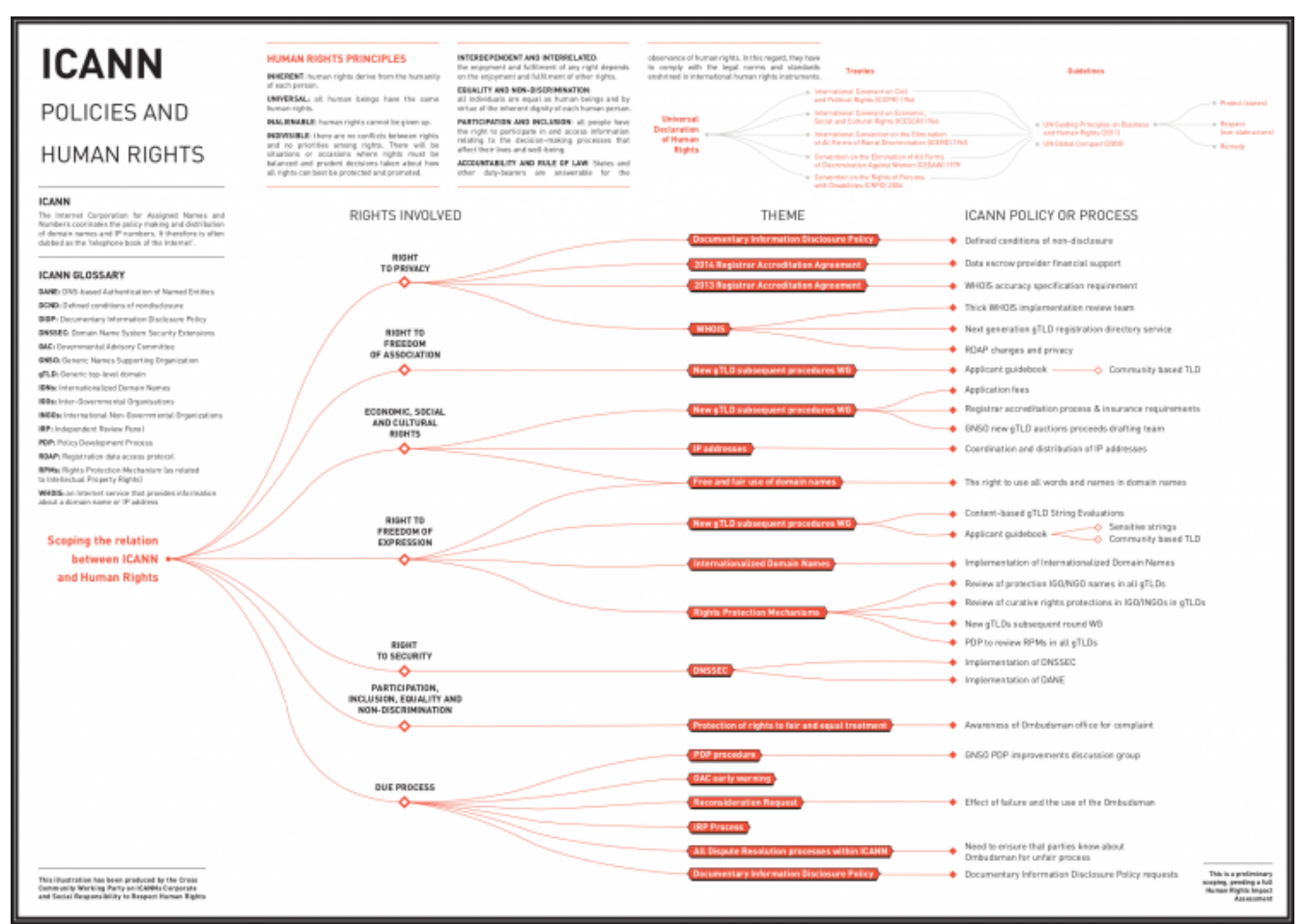

Figure 1: An overview of the relation between human rights, themes and policies/processes in ICANN, prepared by CCWP HR.

\section{NCUC: A COMMUNITY IN EXPANSION}

Mailing lists constitute the main meeting point and organisation and discussion ground for ICANN constituencies and their membership. Examining the evolution of participation is key to understand civil society dynamics around ICANN.12 By analysing traffic volume on NCUCdiscuss, we identified two peaks of traffic, corresponding respectively to the NCUC inception and to the period 2014-present (figure 2). We link the recent growth in NCUC membership to the political opportunities (Tarrow, 1998) brought about by the CoE report, the Global Multistakeholder Meeting on the Future of Internet Governance (NetMundial, São Paulo, Brazil, 2014), the Snowden revelations, and especially the IANA transition - which attracted the attention of civil society advocates who had to date kept ICANN at a distance, notwithstanding their commitment to digital rights. The increase in membership corresponded to a growing diversification in geographical origin, with a new cluster of NCUC active members from the Asia Pacific region. 


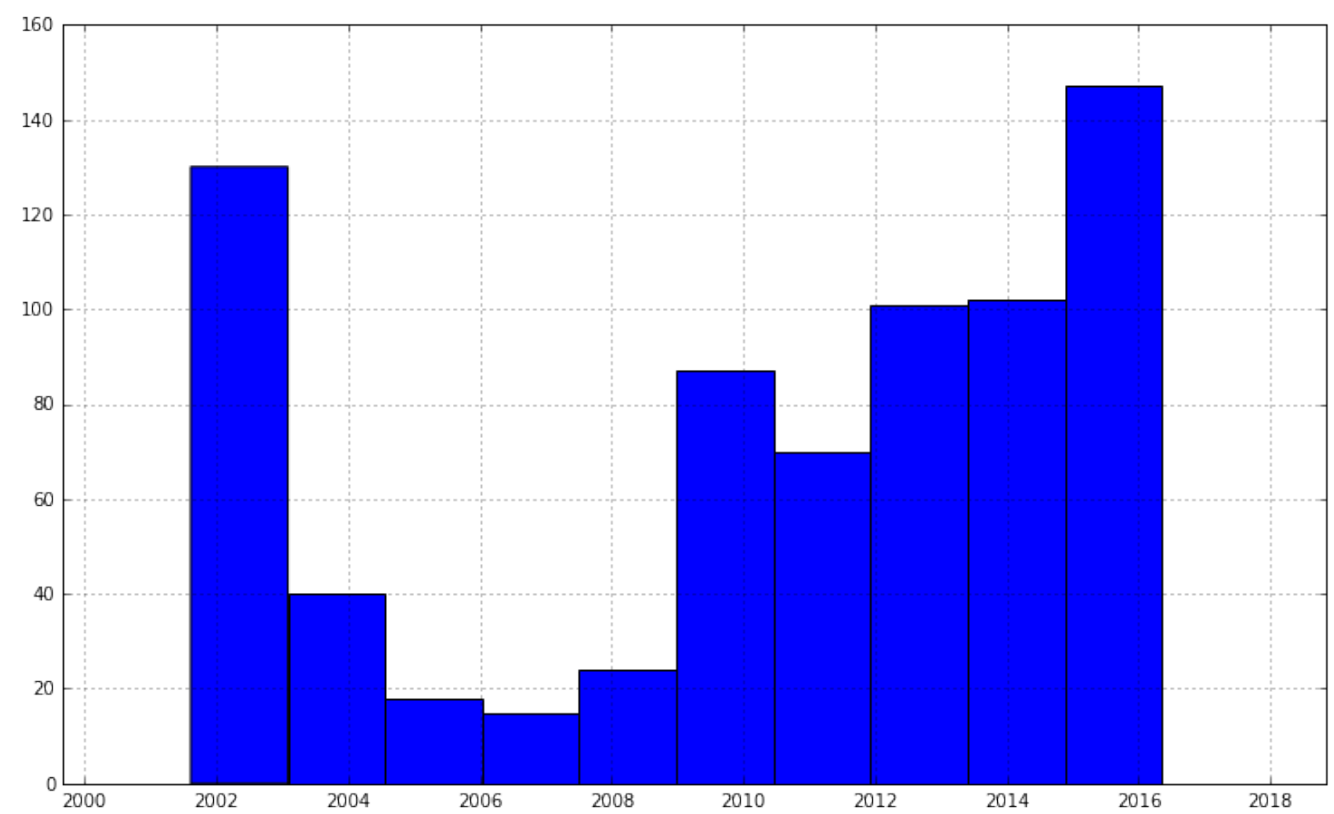

Figure 2: Growth of the NCUC community as reflected in NCUC-discuss (unit of analysis: e-mails from members who made their first post to ncuc-discuss).

Further analysis, linking individual participants' first e-mail to the list with their further participation to the online discussion, allows us to identify three groups of members (figure 3 ). Group o (in red) corresponds to the early days of the NCUC foundation; some members are still active today. Group 1 (in orange) relates to a second phase in the NCUC evolution, with membership from the Global South increasing and new issues entering the agenda, concerning e.g. the new round of allocation of generic Top Level Domain Names (gTLDs) that kicked off in 2010-12. Group 3, including yet another round of new participants (in grey), parallels the IANA transition and the other recent political opportunities described above.

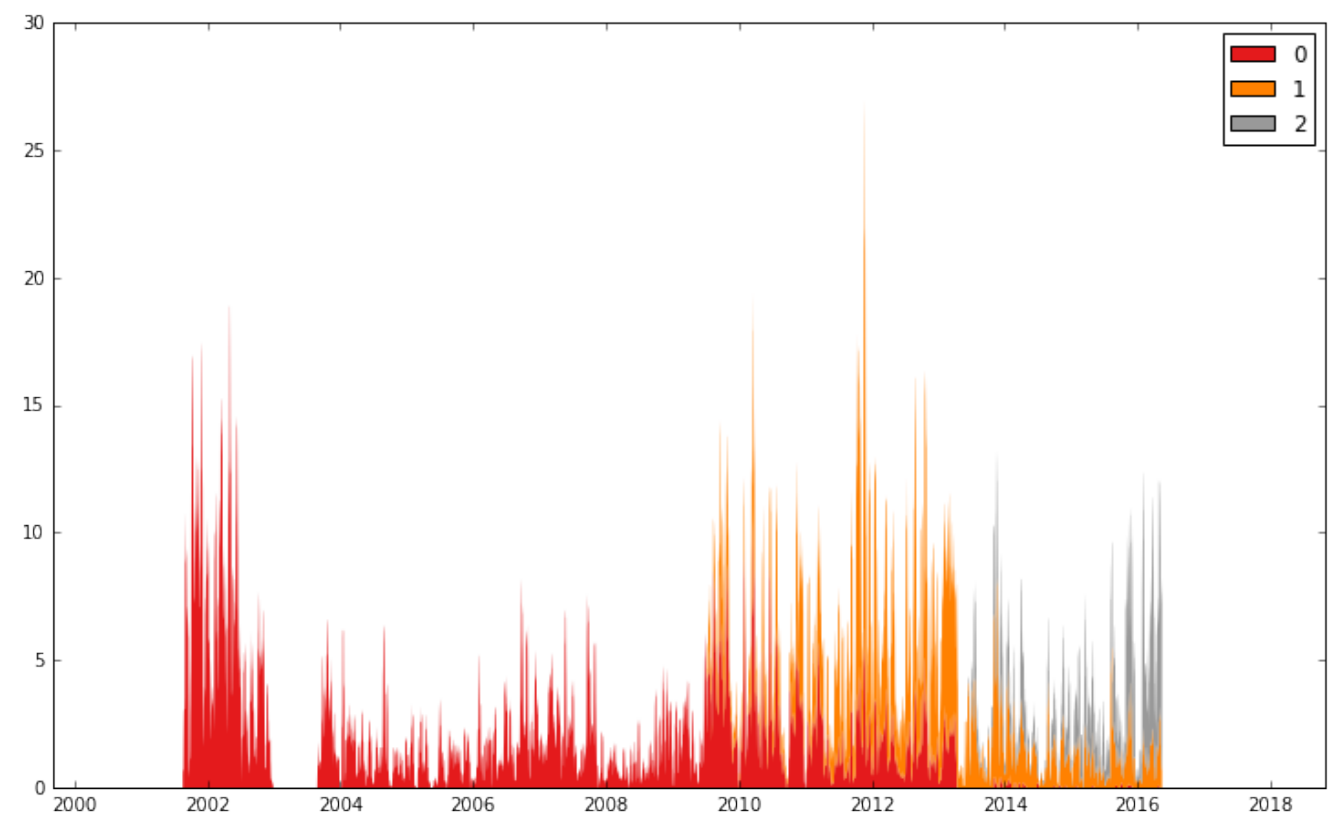

Figure 3: Relation between different groups of participants to ncuc-discuss. E-mails were divided into three cohorts based on when members sent their first e-mail to the list.

We interpret these groups as three cohorts of civil society advocates in ICANN, which, as we 
shall see next, correspond to the progressive broadening of the advocacy agenda. Cohorts 2 and 3 could build on the institution-building and advocacy activities of the previous one(s), enjoying the expertise, structures and resources available over time thanks to internal lobbying (e.g., travel support for civil society advocates, infrastructure for remote participation and conference calls, translation services, and the list goes on).

These findings can be interpreted in light of earlier analyses pointing to a recent adjustment in membership for the civil society engaged in internet governance. Traditional internet governance venues are increasingly subject to the attention of digital rights activists and hackers. The Snowden revelations, but also processes like NetMundial, have determined a shift in the agendas and strategies of civil society actors, to the point of partially reconfiguring traditional equilibriums (Milan, 2014a, 2014b). This represents an innovation with respect to the post-WSIS phase, characterised by a marginalisation of grassroots internet activists, who privileged a hands-on approach that prioritised technology design over policy design (Milan \& Hintz, 2013).

\section{THE EVOLUTION OF SOCIOTECHNICAL IMAGINARIES}

Mailing lists serve as a critical communication and deliberation infrastructure for ICANN constituencies and their membership, representing a crucial venue to investigate discursive change, albeit not the only channel of conversation.13 We postulate a relation between the participation of new members to the discussion and the evolution of human rights discourse. In other words, the change of pace that affected the way human rights were framed and presented to the broader ICANN community, is a function of the inclusion of new members within NCUC and by extension, of the novel policy windows that became available over time. We argue that the three cohorts of advocates we identified correspond roughly to three distinct sociotechnical imaginaries, which we now move to describe with the support of discourse analysis. These are to be seen as simplified ideal-types useful to depict the trajectory of human rights at ICANN, but there are no shift interruptions between the three. Rather, the civil society agenda is cumulative: visions and political preferences do not replace each other but co-exist and dialogue. For the sake of brevity, we highlight only a small selection of representative issues amongst the many advocates fought for over time.

2002-2009. Freedom of expression as a barrier to expansive IP rights. The early civil society advocacy agenda focused on the fight against the strategy of IP protection enacted by ICANN to the detriment of noncommercial interests. It was indeed the observation that 'Trademark claims were limiting legitimate uses of words and concepts in the domain name space' (Mueller, 2012), that prompted freedom of speech advocates to create a space for civil society within ICANN what is now the NCUC. To be safeguarded were the (then) three million .org domain name holders, plus users and potential registrants. The advocacy agenda included freedom of expression, consumer protection, 'trademark maximalism' (Mueller, 2012),ICANN's mission creep (in particular with respect to content regulation), transparency, and the power unbalance between commercial and noncommercial players. Qualitative analysis of the list reveals that activists mostly reacted to upcoming and potential threats at the level of policy-making and institutional design, resisting incumbent regulations by means of discursive tactics oriented to 'reorder' narratives and trying to secure a voice for noncommercial players in an organisation that was still designing itself.

With its emphasis on boundless freedom of expression and individual rights, the sociotechnical 
imaginary of this first cohort evoked libertarianism and the US First Amendment. Civil liberties, rather than human rights, were the main frame of reference, infused with the idea of the internet as enabler of individual rights and free expression. Privacy came in as a function of the latter, in turn rooted in a fierce distrust for governments. This version of cyberlibertarianism resonates with the early cypherpunks (Greenberg, 2013) and with the tech movements of the 1960/70s (Flichy, 2007). The discourse, however, appears more complex if we separate rhetoric from content. While the rhetoric was indeed libertarian, and emphasised negative freedoms such as the protection of users against powerful institutions (both state and commercial players), the narrative was permeated by positive freedoms: advocates supported progressive ideas like user participation within a libertarian strategy - in a novel configuration similar to what, in a different context, Fuchs (2014) has termed 'social cyberlibertarianism'.

2009-2014. Beyond freedom of expression: privacy, due process, social and economic rights. The second cohort of civil society advocates contributed to consolidate the voice and the standing of the constituency. Membership and diversity increased as new professionals joined, including technical experts but also organisations and individual activists with a hacker or human rights background. The liberal rights discourse expanded towards a broader definition of freedom of expression, which came to include neighbouring issues like privacy, due process, and social and economic rights. The strategy remained largely defensive as far as human rights were concerned, with advocates trying to offset threats and expand the discourse to include, for example, development issues. Sadly, the bulk of the ICANN community did not seem to take user rights seriously, as this reflection on the gTLDs auction procedure illustrates: 'Deep pockets win / communities lose / but no one in power at ICANN cares about communities / and if there had been applicants from developing countries they would also lose / and no one in power at ICANN cares about developing economies'. The concerns about the gTLDs programme by large nonprofits like the International Red Cross, and the subsequent creation of NPOC, added complexity to the game, with competing views on, among others, privacy. Due process within ICANN itself was of concerns to advocates, too, as this account relays: 'ICANN is insufficiently accountable to relevant noncommercial interests. [They] are not given the appropriate representation (...) There is a real worry that ICANN is an "industry organization"'. Overall, advocates expressed concern about 'The broader fit between ICANN's actions/policies and the sort of public interest values we're all here to champion'. The prevailing sociotechnical imaginary expanded from a libertarian to a 'classical' human rights agenda, although rights were typically mobilised independently from each other and without a reference to the overall human rights programme, which was seldom explicitly invoked and largely upon initiative of single individuals. The notion of human rights of this period approximates the International Covenant on Economic, Social and Cultural Rights.

2014-present. Waving the digital rights banner: human rights at the forefront. This 'third cohort' took a significant leap forward in the struggle to inscribe human rights into infrastructure and institutional design at ICANN. Exploiting novel policy windows and opportunities for engagement, larger non-profit organisations with a digital rights agenda joined NCUC, including the Center for Democracy \& Technology, the Centre of Internet and Society, the Electronic Frontiers Foundation andAccess Now. The increased organisational membership - able to mobilise resources, thus ensuring continuity of engagement - was coupled by a growing participation of vocal individuals from the global South. These advocates built on the longstanding members' expertise, but their limited familiarity with unwritten community norms prompted them to occasionally bypass established practices to advance their goals. Strategywise, they reacted to threats but especially actively sought opportunities and created the conditions for advancing their cause. They connected human rights with the notion of corporate 
social responsibility; bridged over to other policy fora, and 'reordered' the narrative by other means (e.g. amovie) and through strategic alliances (e.g., cross-community engagement with $\mathrm{CoE}, \mathrm{GAC}$ and other constituencies,participation in academic conferences). Human rights permeated institutional design also with a push for an ICANN privacy policy.

This third cohort includes human rights supporters who do not hesitate to evoke human rights by their name. They also have a much broader human rights agenda inspired to recent notions of digital rights as well as the International Covenant on Civil and Political Rights, foregrounding for instance cultural rights, such as linguistic diversity. These ideas are grounded in a profound understanding of the materiality of the infrastructure, and of its surveillance and control affordances. The human rights agenda is not embraced by the entire NCUC, and there exists criticism concerning the value and potential limitations of a human rights approach (e.g. Mueller, 2016). In fact, views by government representatives coexist with hacker hands-on attitudes and 'social cyberlibertarian' perspectives, in a combination that sets aside dogmatism in favour of a pragmatic preference for flexible, ad hoc alliances and informal collaborations across constituencies.

\section{CONCLUSIONS}

Focusing on the emergence and contestation of new ideas, this article offered a snapshot into the concerted efforts of a group of advocates to wire human rights into the policies (the infrastructure) and procedures (the institution) of ICANN, seen as a site 'for the testing and reaffirmation of political culture' (Jasanoff, 2004, p. 40). Embracing bottom-up design as a form of policy advocacy rooted on and inspired to technical practice, NCUC human rights advocates operated as a critical community advancing discursive tactics entrenched in sociotechnical imaginaries. Using novel 'ordering narratives' able to (re)structure relations strategically organised (Law, 1991), they partially managed to subvert mainstream organisational narratives that had thus far been 'recursively told, embodied, and performed' (Law, 1994a, p. 259) by the ICANN community. Paraphrasing Jasanoff, advocates tried to make the organisation by making discourses. Further research could comprise, for instance, a crossconstituency analysis of the evolution over time of the human rights discourse, and a detailed discourse and social-network analysis of ICANN policy development processes as they related to specific human rights and portions of the ICANN infrastructure (e.g. the WHOIS database and its privacy implications).

Echoing Epstein et al. (2016), we believe STS has much to offer in the understanding of the complex ecosystem of internet governance. To name just one of the many promising venues, the STS perspective on ordering as a key organisational mechanism adopted in this article, encouraged us to approach both infrastructure and organisation as sites of contestation and coproduction. It allowed us to illuminate some of the micro practices of governance by civil society actors within ICANN, tracking their meaning-making and discursive role as they unfolded in the NCUC mailing list. Triangulating participant observation with quantitative and qualitative analysis of the main NCUC mailing list, where organisation and deliberation unfold, we identified three ideal-type generations of civil society advocates corresponding to distinct but cumulative ideal-type human rights imaginaries, with their respective agendas and tactics. We showed how the combination of emerging political opportunities and the progressive inclusion of new, diverse members brought about new issues, or new ways of framing certain issues, altering and empowering the emerging 'ordering narratives' from the bottom up. 
We like to think of this struggle as an attempt to explicitly wire the politics of internet architecture into the politics of institutions (see DeNardis, 2012). It can also be seen as an instance of the recent 'turn to infrastructure' in internet governance (Musiani et al., 2016), whereby private actors seek to expand the remit (and the features) of the infrastructure (i.e., the DNS) to positively permeate institutional design (i.e., ICANN). It remains to be seen how the ongoing human rights struggle will evolve over time, and how the stabilisation phase (Jasanoff, 2004) will affect the agenda setting capability of civil society and its role within the ICANN community. 


\section{REFERENCES}

Agre, P. E. (1997). Computation and Human Experience. Cambridge, MA: Cambridge University Press.

Akrich, M. (1992). The De-Scription of Technical Objects. In W. E. Bijker \& J. Law (Eds.), Shaping Technology/Building Society. Studies in Sociotechnical Change (pp. 205-224). Cambridge, MA: MIT Press.

Appelman, D. L. (2016). Internet Governance and Human Rights: ICANN's Transition Away from United States Control. The Clarion, a Journal of the American Bar Association's International Human Rights Committee, 1(1).

Benthall, S. (2015). Testing Generative Models of Online Collaboration with BigBang (pp. 182-189). Presented at the Proceedings of the 14th Python in Science Conference.

Bijker, W. E. (1997). Of Bicycles, Bakelites, and Bulbs. Toward a Theory of Sociotechnical Change. Cambridge, MA and London, England: MIT Press.

Bijker, W. E., \& Law, J. (Eds.). (1992). Shaping Technology/Building Society. Cambridge, MA: MIT Press.

Bygrave, L. (2015). Internet Governance by Contract. Oxford: Oxford University Press.

Cath, C. (2015). A case study of coding rights: should freedom of speech be instantiated in the protocols and standards designed by the Internet Engineering Task Force? (MA dissertation). University of Oxford, Oxford, UK.

Cardoso, F. H. (2004). We the people: Civil society, the United Nations and global governance. Report of the Panel of Eminent Persons on United Nations-Civil society relations. United Nations.

DeNardis, L. (2012). Hidden Levers of Internet Control: An Infrastructure-Based Theory of Internet Governance. Information, Communication \& Society, 15(5), 720-738.

Dery, D. (2000). Agenda setting and problem definition. Policy Studies, 2(1), 37-47.

Doolin, B. (2003). Narratives of change: Discourse, technology and organization. Organization, $10(4), 751-770$.

Dourish, P. (2001). Where the Action Is The Foundations of Embodied Interaction. Cambridge, MA: MIT Press.

Dunne, A., \& Raby, F. (2001). Design Noir: The Secret Life of Electronic Objects. Basel: Birkhäuser.

Epstein, D., Katzenbach, C., \& Musiani, F. (2016). Doing internet governance: how science and technology studies inform the study of internet governance. Internet Policy Review, 5(3).

Flichy, P. (2007). The internet imaginaire. Cambridge, Mass.: MIT Press.

Flyverbom, M. (2011). The Power of Networks: Organizing the Global Politics of the Internet. Cheltenham, UK: Edward Elgar. 
Flyverbom, M. (2016). Disclosing and concealing: internet governance, information control and the management of visibility. Internet Policy Review, 5(3).

Greenberg, A. (2013). This Machine Kills Secrets: Julian Assange, the Cypherpunks, and Their Fight to Empower Whistleblowers (Reprint edition). New York: Plume.

Hess, D. J. (2005). Technology-and product-oriented movements: Approximating social movement studies and science and technology studies. Science, Technology \& Human Values, $30(4), 515-535$.

Hintz, A. (2009). Civil Society Media and Global Governance: Intervening into the World Summit on the Information Society. Münster: Lit.

Hintz, A., \& Milan, S. (2009). At the margins of Internet governance: grassroots tech groups and communication policy. International Journal of Media \& Cultural Politics, 5(1/2), 23-38.

Hoffmann, J., Katzenbach, C., \& Gollatz, K. (2016). Between coordination and regulation: Finding the governance in Internet Governance. New Media \& Society.

ICANN. (2016, February 11). Bylaws for Internet Corporation for Assigned Names and Numbers | A California Nonprofit Public-Benefit Corporation. Retrieved from https://www.icann.org/resources/pages/bylaws-2016-02-16-en

Jasanoff, S. (Ed.). (2004). States of Knowledge: The Co-production of Science and the Social Order. New York: Routledge.

Jasanoff, S., Kim, S.-H., \& Sperling, S. (2007). Sociotechnical Imaginaries and Science and Technology Policy: A Cross-National Comparison. NSF Research Project, Harvard University.

Jørgensen, R. F. (2006). Human rights in the global information society. Cambridge, MA: MIT Press.

Kingdon, J. W. (1995). Agendas, Alternatives and Public Policies. New York: Longman.

Law, J. (1991). Power, Discretion and Strategy. In J. Law (Ed.), A Sociology of Monsters: Essays on Power, Technology and Domination (pp. 165-191). London: Routledge.

Law, J. (1994a). Organization, Narrative and Strategy. In J. Hassard \& M. Parker (Eds.), Towards a New Theory of Organizations (pp. 248-68). London: Routledge.

Law, J. (1994b). Organizing modernity. Oxford, UK Cambridge, Massachusetts, USA: Blackwell.

MacKenzie, D., \& Wajcman, J. (Eds.). (1999). The Social Shaping of Technology (2nd ed.). Buckingham and Philadelphia: Open University Press.

McCharty, D. R. (2011). Open Networks and the Open Door: American Foreign Policy and the Narration of the Internet. Foreign Policy Analysis, 7, 89-111.

Milan, S. (2009). Community Media activists in Transnational Policy Arenas: Strategies and Lessons Learnt. In K. Howley (Ed.), Understanding Community Media (pp. 308-317).

Thousand Oaks, CA: Sage. 
Milan, S. (2014a, April 24). NETmundial: Is there a new guard of civil society coming to the internet governance fora?, CGCS Media Wire

Milan, S. (2014b, September 10). The Fair of Competing Narratives: Civil Society(ies) after NETmundial, CGCS Media Wire

Milan, S., \& Hintz, A. (2013). Networked Collective Action and the Institutionalized Policy Debate: Bringing Cyberactivism to the Policy Arena? Policy \& Internet, 5(1), 7-26.

Mol, A. (2001). The Body Multiple: Ontology in Medical Practice. Durham and London: Duke University Press.

Mueller, M. L. (2002). Ruling the root Internet governance and the taming of cyberspace. Cambridge, Mass.: MIT Press.

Mueller, M. L. (2010). Networks and States. The Global Politics of Internet Governance. Cambridge, MA and London, England: MIT Press.

Mueller, M. L. (2012, October). Brief History of NCUC, NCUC.org

Mueller, M. L. (2016, October 26). Missing the Target: The Human Rights Push in ICANN goes off the rails. Internet Governance Project Blog.

Musiani, F. (2015). Practice, Plurality, Performativity, and Plumbing: Internet Governance Research Meets Science and Technology Studies. Science, Technology \& Human Values, 4O(2), 272-288.

Musiani, F. (2016). Alternative Technologies as Alternative Institutions: The Case of the Domain Name System. In F. Musiani, D. L. Cogburn, L. DeNardis, \& N. S. Levinson (Eds.), The Turn to Infrastructure in Internet Governance (pp. 73-86). Basingstoke, UK: Palgrave Macmillan.

Musiani, F., Cogburn, D. L., DeNardis, L., \& Levinson, N. S. (2016). The Turn to Infrastructure in Internet Governance. Basingstoke, UK: Palgrave Macmillan.

Padovani, C., Musiani, F., \& Pavan, E. (2010). Investigating Evolving Discourses On Human Rights in the Digital Age Emerging Norms and Policy Challenges. International Communication Gazette, 72(4-5), 359-378.

Parks, L. (2015). "Stuff you can kick": Toward a theory of media infrastructure. In P. Svensson \& D. T. Goldberg (Eds.), Between Humanities and the Digital (pp. 355-373). Cambridge, MA and London, England: MIT Press.

Pavan, E. (2012). Frames and connections in the governance of global communications: A network study of the internet governance forum. Lanham, MA: Lexington Books.

Raymond, M., \& DeNardis, L. (2015). Multistakeholderism: Anatomy of an Inchoate Global Institution. International Theory, 7(3), 572-616.

Rochon, T. R. (1998). Culture Moves. Ideas, Activism, and Changing Values. Princeton, NJ: Princeton University Press.

Scholte, J. A. (2016). Process and power in Internet governance. Reflections on the IANA transition. Presented at the RIPE, Amsterdam. 
Stone, D. A. (1988). Policy, paradox and political reason. New York: HarperCollins.

Tarrow, S. (1998). Power in Movement. Social Movements and Contentious Politics. Cambridge: Cambridge University.

Tréguer, F., Panayotis, A., \& Söderberg, J. (Eds.). (2016). Alternative Internets. Journal of Peer Production, 9.

Turner, F. (2006). From counterculture to cyberculture: Stewart Brand, the Whole Earth Network, and the rise of digital utopianism. Chicago: University of Chicago Press.

Van Eeten, M. J., \& Mueller, M. L. (2013). Where is the governance in Internet governance? New Media \& Society, 15(5), 720-736.

Woolgar, S., \& Neyland, D. (2013). Mundane governance: Ontology and accountability. Oxford: Oxford University Press.

Zalnieriute, M., \& Schneider, T. (2014). A Council of Europe analysis on ICANN's procedures and policies in the light of human rights, fundamental freedoms and democratic values. Strasbourg: Council of Europe.

\section{FOOTNOTES}

1. For an overview of STS in internet governance research see the Internet Policy Review special issue 'Doing Internet Governance: practices, controversies, infrastructures, and institutions', available at: https://policyreview.info/articles/analysis/doing-internet-governance-practicescontroversies-infrastructures-and-o

2. See also Law (1994b).

3. 'Bottom-up' here is intended to evoke also the bottom-up process of ICANN itself, as we shall see in what follows. Although it does not equal grassroots participation and there is still limited civil society involvement in ICANN, we observe a slow increase in the participation of grassroots organisations from different backgrounds - as testified by the expanding organisational membership in the Noncommercial Users Constituency (NCUC) and in the number of advocates with grassroots activism or hacker backgrounds - a trend observed also in other internet governance venues (Milan, 2014a).

4. Illustrating the evolution and uses of the notion of ordering goes beyond the scope of this article. For an overview see Flyverbom (2011, 2016); Hoffmann, Katzenbach, \& Gollatz (2016).

5. See lists.ncuc.org/cgi-bin/mailman/listinfo/ncuc-discuss. The e-mail list, which built on the pre-existing NCDNHC list later renamed, is the main venue for NCUC members to exchange views and strategise. Open to members only but publicly archived, members are subscribed by default upon joining NCUC. Ncuc-discuss archives include also e-mails from the period immediately before NCUC was formally established, including e-mails from ncdnhc-discuss for 2002-2003.

6. Both authors are active within the ICANN civil society sector. Milan represents noncommercial users in the Council of the Generic Names Supporting Organization (GNSO), thus contributing to policy development in the generic domains space; ten Oever is the chair of the Cross Community Working Party on ICANNs Corporate and Social Responsibility to Respect Human Rights (CCWP HR). As such he played a key role in advancing the human rights 
discourse.

7. 'Civil society' indicates the realm of human activity outside the remit of the state and the market (see Cardoso, 2004).

8. These collective visions have also been approached as, e.g., discourses (Padovani, Musiani, \& Pavan, 2010), frames (Pavan, 2012), and narratives (McCharty, 2011).

9. Together with the Not-for-Profit Operational Concerns Constituency (NPOC), NCUC constitutes the Non Commercial Stakeholder Group (NCSG). NCSG elects the six GNSO councilors representing civil society. A third entity, the At-Large Advisory Committee (ALAC), represents users' interests. NPOC and ALAC are not considered here for they have not been particularly vocal in the human rights debate.

10. CCWPs are ad hoc, informal single-issue groups with no official policy development or advisory power.

11. Section 27.2 sets some procedural limitations for the human rights bylaw, including their coming into force pending the development of a framework of interpretation.

12. NCUC recent membership includes digital rights organisations like the Electronic Frontier Foundation and Access Now, freedom of expression organisations like Article 19 and Free Press, but also the American Civil Liberties Union, the Centre for Internet and Society (Bangalore, India), and the Washington-based Center for Democracy \& Technology. A close reading of organisational membership over time would nicely complement our automated analysis of mailing list traffic, but it is outside the scope of this article.

13. By focusing on one constituency-based mailing list, this study fails to capture the contentious process of negotiation across constituencies, and this represents the main limitation of this approach. However, by concentrating on that main civil society avenue within ICANN that also happens to drive the bottom-up design efforts described here, the article offers a snapshot into the behind-the-scenes of the ongoing process of discursive change that has human rights at its core. 